\title{
PEMBUATAN BRIKET DARI SAMPAH PERTANIAN SEBAGAI UPAYA MENINGKATKAN PENDAPATAN MASYARAKAT DESA
}

\author{
SRI SURYANINGSIH ${ }^{1 *}$, OTONG NURHILAL ${ }^{1}$, RUKIAH $^{2}$ \\ ${ }^{1}$ Departemen Fisika, \\ ${ }^{2}$ Departemen Kimia \\ Fakultas Matematika dan Ilmu Pengetahuan Alam, Universitas Padjadjaran \\ Jl. Raya Bandung-Sumedang Km 21, Jatinangor 45363 \\ *email : sri@phys.unpad.ac.id
}

\begin{abstract}
Abstrak. Telah dilakukan rancang bangun alat pencetak briket portable dengan tujuan untuk mengoptimalkan pemafaatan sampah dan limbah pertanian yang tersedia menjadi bahan bakar briket yang ramah lingkungan, sehingga dapat meningkatkan nilai ekonomis sampah dan limbah pertanian tersebut. Alat pencetak briket portable didesain sederhana agar masyarakat desa dapat lebih mudah membuat, serta penggunaan bahan bakar briket secara aman dan benar. Diharapkan briket dari sampah sebagai bahan bakar alternatif yang cukup berkualitas, pengganti minyak tanah dan EPG. Briket yang baik memiliki laju pembakaran yang lama sebesar $0,0097 \mathrm{gr} / \mathrm{s}$ dan temperatur yang dihasilkan maksimum sebesar $401,07^{\circ} \mathrm{C}$. Berdasarkan uji coba yang dilakukan pada masyarakat desa, didapatkan briket yang baik digunakan untuk memanaskan air dengan suhu maksimum $98^{\circ} \mathrm{C}$ dan waktu pendidihan 2640 sekon.
\end{abstract}

Kata kunci : sampah, bahan bakar, briket, laju pembakaran

\begin{abstract}
The design of portable briquette molding equipment has been carried out with the aim of optimizing the utilization of available waste and agricultural waste into environmentally friendly briquette fuel, so as to increase the economic value of waste and agricultural waste. The portable briquette printer is designed simply, so that the village community can more easily make and use briquette fuel safely and correctly. It is expected that briquettes from garbage are a good enough alternative fuel, a substitute for kerosene and EPG. Good briquettes have a long burning rate of $0.0097 \mathrm{~g} / \mathrm{s}$ and the resulting temperature is a maximum of $401.07^{\circ} \mathrm{C}$. Based on the trials carried out in the village community, a good briquette was used to heat water with a maximum temperature of $98^{\circ} \mathrm{C}$ and boiling time of 2640 seconds.
\end{abstract}

Keywords : garbage, fuel, briquettes, burning rate

\section{Pendahuluan}

Desa Cilayung merupakan salah satu desa yang dijadikan objek untuk melaksanakan program Pengabdian Pada Masyarakat yang terintegrasi dengan Kuliah Kerja Nyata Mahasiswa (PPM-Integratif) Universitas Padjadjaran. Setelah melakukan survey dan observasi di Desa Cilayung, kemudian dilanjutkan dengan sosialisasi kepada perangkat Desa, didapatkan bahwa masyarakat Desa Cilayung khususnya ibu-ibu rumah tangga memiliki pengetahuan yang terbatas mengenai pengelolaan sampah rumah tangga maupun limbah dari hasil perkebunan dan pertanian. Untuk dapat meningkatkan pemahaman akan manfaat lain dari sampah menjadi berharga bagi keluarga, maka masyarakat perlu dibekali dengan pengetahuan dan keterampilan yang cukup. Situasi lain yang ada di Desa Cilayung 
Kecamatan Jatinangor adalah ketersediaan gas LPG yang tidak menentu, sehingga ada saat dimana kelangkaan gas LPG terjadi di Desa Cilayung.

Seiring dengan tingginya pertumbuhan penduduk, maka akan semakin banyak sampah yang dihasilkan. Volume timbunan sampah baik jenis organik maupun anorganik akan terus meningkat tiap harinya. Hal ini menimbulkan beberapa pemikiran permasalahan antara lain:

- Bentuk usaha apa yang akan disumbangkan kepada masyarakat agar dapat memanfaatkan sampahnya sendiri

- Masukan apa yang dapat diterima oleh masyarakat dalam pengelolaan sampah

- Bentuk penerangan dan pelatihan yang bagaimana akan diberikan kepada masyarakat sehingga diharapkan mereka dapat mengerti tentang pentingnya dalam memanfaatkan teknologi bahan bakar dari sampah menjadi briket tersebut secara baik dan aman

Briket arang merupakan bahan bakar padat terbuat dari biomassa yang diarangkan dengan proses karbonisasi [1]. Suhu pembakaran yang lebih tinggi dapat menaikkan laju reaksi dan menyebabkan waktu pembakaran menjadi lebih singkat [2]. Laju pembakaran dalam proses pembakaran briket dengan cara membakar briket untuk mengetahui lama nyala suatu bahan bakar kemudian menimbang massa briket yang terbakar. Lamanya waktu penyalaan dan massa briket [3].

Oleh karena itu perlu sosialisasi pemberian teknologi tepat guna pembuatan briket dalam menghasilkan bahan bakar yang ramah lingkungan. Tujuan dari sosialisasi ini adalah agar masyarakat lebih memperhatikan dalam tata cara pembuatan bahan bakar briket beserta dengan perangkat lainnya, seperti alat cetak briket dan kompor briket. Sosialisasi ini juga bertujuan untuk mentransfer pengetahuan tentang penggunaan bahan bakar briket secara aman dan benar. Program ini pada akhirnya diharapkan briket dari sampah sebagai bahan bakar alternatif yang cukup berkualitas, pengganti minyak tanah dan EPG.

\section{Metode Penelitian}

Pembuatan briket terdiri atas tiga tahapan terdiri dari tahapan persiapan alat pencetak briket sederhana didesain dengan biaya pembuatan dan pemeliharaan yang sangat murah. Kemudian alat yang telah dibangun tersebut diujicoba menggunakan sampah atau limbah pertanian yang berasal dari daerah Cilayung Kecamatan Jatinangor Kabupaten Sumedang. Briket yang dihasilkan diujicoba kemampuan nyala dengan kompor briket untuk mendidihkan air.

Rancangan alat pencetak briket terdiri dari 3 bagian utama yaitu tempat sampel briket berbentuk tabung terbuat dari pipa besi volume $166 \mathrm{~cm}^{3}$, tinggi $12 \mathrm{~cm}$, dan diameter 4,23 cm sebanyak 12 buah, pompa hidrolik sebagai pemberi daya tekan pada sampel briket agar padat dengan kekuatan tekan mencapai 10 Psi. Ujicoba alat pembuatan briket dilakukan di Departemen Fisika FMIPA Unpad. Sampel uji yang digunakan adalah sekam padi yang diperoleh dari Desa Cilayung Kecamatan Jatinangor Kabupaten Sumedang yang sudah dikeringkan. 
Tahapan persiapan bahan briket terdiri persiapan tungku pembakaran, sampel sekam padi diarangkan dalam tungku pembakaran dengan metode pirolisis (karbonisasi) dengan suhu $200^{\circ} \mathrm{C}$ selama 150 menit. Pada Gambar 1 menunjukkan tungku pembakaran briket menggunakan drum dengan diameter $57 \mathrm{~cm}$ dan tinggi $85 \mathrm{~cm}$. Selanjutnya proses penghalusan sampel dan penyaringan untuk menentukan ukuran butir sampel dengan menggunakan saringan 60 mesh $(250 \mu \mathrm{m})$.

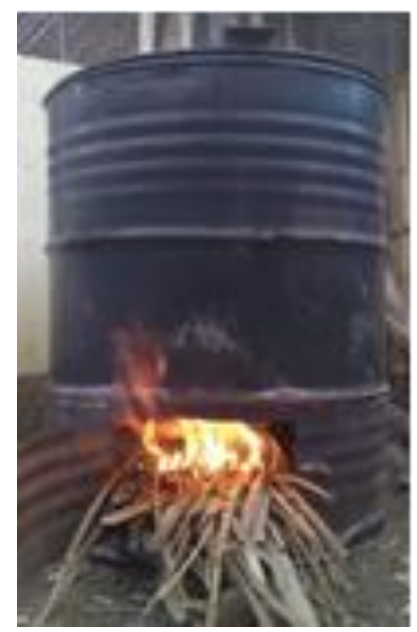

Gambar 1. Tungku pembakaran untuk karbonisasi sekam padi

Tahap pembuatan briket dari arang sekam padi dilakukan dengan mencampurkan arang sekam padi halus 100 gram dan larutan campuran air dan perekat $7 \%$. Untuk perekat terdiri dari tepung kanji dan air dengan perbandingan 1 gram:10 ml. Selanjutnya bahan diaduk hingga merata menjadi adonan yang siap untuk dicetak menggunakan alat cetak briket supaya padat.

Tahapan pengujian nyala briket menggunakan kompor briket. Pengujian karakteristik pembakaran briket dilakukan dengan memasukkan briket kedalam tempat pembakaran briket didalam kompor briket dan mengatur kecepatan udara yang dihasilkan pada blower yaitu sebesar $0,8 \mathrm{~m} / \mathrm{s}, 1,1 \mathrm{~m} / \mathrm{s}, 1,2 \mathrm{~m} / \mathrm{s}, 1,3 \mathrm{~m} / \mathrm{s}$ dan $1,4 \mathrm{~m} / \mathrm{s}$. Laju pembakaran dapat dihitung menggunakan persamaan (1) dengan mencatat waktu, temperatur pembakaran dan massa briket terbakar.

Laju pembakaran $($ gram/sekon $)=\frac{\text { Massa briket terbakar }(\text { gram })}{\text { waktu pembakaran }(\text { sekon })}$

Pengujian briket untuk mendidihkan air sebanyak 1 liter yaitu untuk mengetahui waktu yang dibutuhkan untuk mendidihkan air dan temperatur briket dan air.

\section{Hasil dan Pembahasan}

\subsection{Hasil Uji Alat Pencetak Briket}

Hasil rancangan alat pencetak briket terdiri dari 3 bagian utama yaitu tempat sampel berupa sekam padi yang telah dibuat arang berbentuk tabung dengan ukuran tinggi $12 \mathrm{~cm}$ dan diameter $4,23 \mathrm{~cm}$ sebanyak 12 buah, pompa hidrolik sebagai pemberi daya tekan pada sampel briket agar padat. Alat cetak briket yang sudah terintegrasi dapat dilihat pada Gambar 2. 
Tekanan pompa dapat dibaca pada pressure gauge yang terpasang pada pompa hidrolik. Ketika dihadapkan pada persoalan pompa hidrolik yang berhubungan dengan piston dan silinder headnya, maka ada perhitungan gaya hidrolik dan diameter pipa silinder dan diameter piston.

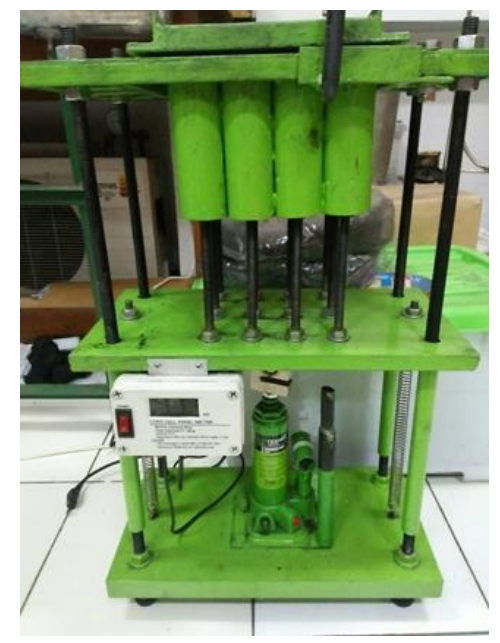

Gambar 2. Alat Pencetak Briket

Sebelumnya sekam padi sebagai sampel uji dibuat arang dengan tungku pembakaran hasil karbonisasi. Pada proses karbonisasi ini terdapat penyusutan massa dari bahan, massa awal sekam padi sebesar $10 \mathrm{~kg}$ dan setelah dikarbonisasi menghasilkan massa akhir sebesar 5,2 kg. Selanjutnya bahan arang dihaluskan menggunakan blender selama 1-2 menit agar ukurannya lebih kecil, kemudian dilakukan penyaringan arang untuk memperoleh ukuran partikel arang sebesar 60 mesh. Hasil arang yang sudah halus kemudian disimpan dalam suatu kontainer agar tetap kering.

Tabel 1. Karakteristik Alat Pencetak Briket

\begin{tabular}{cccccc}
\hline Uji & $\begin{array}{c}\text { Massa } \\
(\text { gram) }\end{array}$ & $\begin{array}{c}\text { Tinggi } \\
(\mathbf{c m})\end{array}$ & $\begin{array}{c}\text { Diameter } \\
(\mathbf{c m})\end{array}$ & $\begin{array}{c}\text { Beban } \\
(\mathbf{k g})\end{array}$ & $\begin{array}{c}\text { Tekanan } \\
(\text { Psi) }\end{array}$ \\
\hline 1 & 116 & 8.86 & & 45,92 & 4,46 \\
2 & 120 & 9.28 & & 39,25 & 3,81 \\
3 & 100 & 8.49 & 4,23 & 36,17 & 3,51 \\
4 & 115 & 9.54 & & 43,42 & 4,22 \\
5 & 85 & 7.82 & & 74,83 & 7,27 \\
\hline
\end{tabular}

Tabel 1 memperlihatkan hasil uji karakterisasi alat pencetak briket dari lima sampel uji dengan massa bahan briket yang berbeda menunjukkan semakin besar massa memerlukan tekanan yang besar, hal ini terkait dengan nilai densitas rata-rata bahan sebesar $0,624 \mathrm{gr} / \mathrm{cm}^{3}$. 


\subsection{Hasil Uji Briket Mendidihkan Air 1 Liter}

Gambar 3 menunjukkan kompor briket yang sederhana dilengkapi pengatur kecepatan udara pada blower yaitu sebesar $0,8 \mathrm{~m} / \mathrm{s}, 1,1 \mathrm{~m} / \mathrm{s}, 1,2 \mathrm{~m} / \mathrm{s}, 1,3 \mathrm{~m} / \mathrm{s}$ dan $1,4 \mathrm{~m} / \mathrm{s}$. Uji coba pengoperasian kompor briket dilakukan di Departemen Fisika FMIPA Unpad. Sampel uji yang digunakan adalah briket arang sekam padi yang telah dikeringkan.

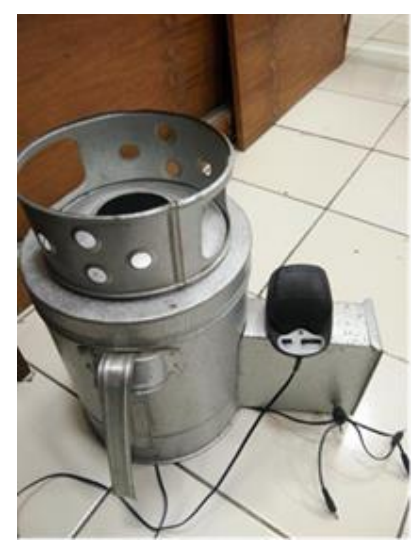

Gambar 3. Kompor Briket Portable

Berdasarkan ujicoba kemampuan briket mendidihkan air sebanyak 1 liter yaitu untuk mengetahui waktu yang dibutuhkan untuk mendidihkan air dan temperatur optimum. Hasil uji coba kemampuan satu briket untuk mendidihkan air sebanyak 1 liter mencapai suhu sebesar $92^{\circ} \mathrm{C}$ dan waktu pendidihan 80 menit. Hal ini dapat dilihat dari kualitas briket berdasarkan waktu nyala terlama dengan laju pembakaran maksimum terjadi pada menit ke-60 sebesar $0,72 \mathrm{gr} / \mathrm{menit}$ pada kecepatan udara $0,8 \mathrm{~m} / \mathrm{s}$, seperti pada Tabel 2 .

Tabel 2. Kualitas briket berdasarkan waktu nyala dengan laju pembakaran pada variasi kecepatan udara

\begin{tabular}{cccccc}
\hline $\begin{array}{c}\text { Suhu } \\
\left({ }^{\circ} \mathbf{c}\right)\end{array}$ & $\mathbf{v}(\mathbf{m} / \mathbf{s})$ & $\begin{array}{c}\text { Massa Awal } \\
(\mathbf{g})\end{array}$ & $\begin{array}{c}\text { Massa Akhir } \\
(\mathbf{g})\end{array}$ & $\begin{array}{c}\text { Waktu } \\
(\mathbf{m e n i t})\end{array}$ & $\begin{array}{c}\text { Laju } \\
\text { pembakaran } \\
(\mathbf{g} / \text { menit })\end{array}$ \\
\hline \multirow{4}{*}{200} & 0.8 & 68 & 25 & 60 & 0.72 \\
& 1.1 & 67 & 27 & 57 & 0.70 \\
& 1.2 & 62 & 22 & 48 & 0.83 \\
& 1.3 & 65 & 26 & 57 & 0.68 \\
& 1.4 & 63 & 25 & 48 & 0.79 \\
\hline
\end{tabular}

Jika dibandingkan dengan menggunakan bahan bakar lain, maka perlu 5 briket dengan ukuran yang sama dapat mendidihkan air selama 16 menit.

\section{Kesimpulan}

Telah berhasil dibuat pencetak briket yang terintegrasi dengan pompa tekan hidrolik. Uji coba dilakukan dengan sampel sekam padi dari desa Cilayung 
kecamatan Jatinangor Kabupaten Sumedang. Hasil uji coba alat cetak briket memiliki kuat tekan maksimum $1500 \mathrm{~kg}$ (10,5 Psi) untuk 12 cetak sampel. Kemampuan briket untuk mendidihkan air sebanyak 1 liter cukup lama mencapai suhu air sebesar $92^{\circ} \mathrm{C}$ dengan waktu pendidihan 60 menit dan laju pembakaran 0,72 gram/menit.

\section{Ucapan Terima kasih}

Terimakasih kepada Direktorat Riset dan Pengabdian Pada Masyarakat Universitas Padjadjaran yang telah memberikan dana riset dan fasilitas melalui Hibah Pengabdian Pada Masyarakat (PPM-Integratif) no. kontrak: 2377/UN6.D/KS/2018, 16 Maret 2018 Universitas Padjadjaran Tahun Anggaran 2018.

\section{Daftar Pustaka}

1. Sarjono, "Studi Eksperimental Perbandingan Nilai Kalor Briket Campuran Bioarang Sekam Padi dan Tempurung Kelapa," hal. 11-18, 2013.

2. S. Jamilatun, "Sifat-Sifat Penyalaan dan Pembakaran Briket Biomassa, Briket Batubara dan Arang Kayu," Jurnal Rekayasa Proses, Vol. 2 No. 2 (2008) p. 3740.

3. M. A. Almu, Syahrul, dan Y. A. Padang, "Analisa Nilai Kalor dan Laju Pembakaran Pada Briket Campuran Biji Nyamplung (Calophyllm Inophyllum) dan Abu Sekam Padi," Dinamika Teknik Mesin, Vol. 4 No. 2 (2014) p. 117-122.

4. Y. Yuliah, S. Suryaningsih, K. Ulfi, Penentuan Kadar Air Hilang dan volatile Matter pada Bio-Briket dari Campuran Arang Sekam Padi dan Batok Kelapa, Jurnal Ilmu dan Inovasi Fisika Vol. 01 No. 01 (2017) p.51-57. 